\title{
Ist therapeutischer
} Rat zu Medikamenten strafbar?

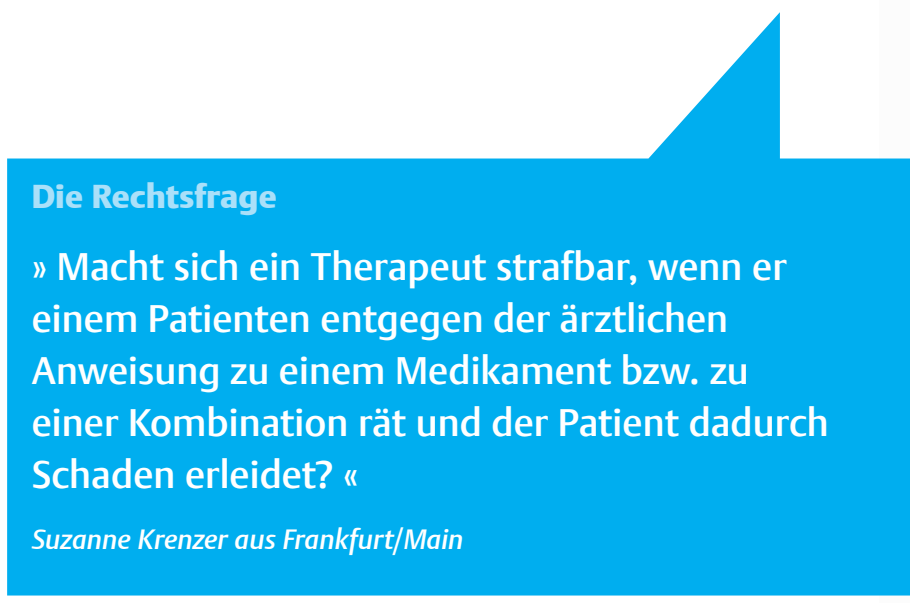

\section{Die Antwort unseres Experten}

Zunächst kommt es darauf an, ob der Therapeut zu einem verordnungspflichtigen Medikament rät. In diesem Fall müsste ein Arzt dieses Medikament verordnen und damit auch die Verantwortung übernehmen.

Rät der Therapeut entgegen der ärztlichen Meinung zu einem nicht verschreibungspflichtigen Arzneimittel, kann er aufgrund fahrlässiger Körperverletzung oder fahrlässiger Tötung strafrechtlich zur Verantwortung gezogen werden. Hierzu müsste der Therapeut allerdings erkennen, dass das Medikament im Zusammenhang mit der konkreten Erkrankung des Patienten und den sonstigen Umständen zu Schäden führen kann. Darüber hinaus kommt es darauf an, in welchem Maß der Patient dem Therapeuten vertraut und ob dies für den Therapeuten erkennbar ist. Denn: Sofern der Therapeut lediglich eine unverbindliche Empfehlung oder Meinung äußert und dies dem Patienten auch unmissverständlich zu verstehen gibt, hat er strafrechtlich nicht dafür einzustehen, denn der
Patient weicht dann eigenverantwortlich vom ärztlichen Rat ab. In einem Strafverfahren müsste der Staat beweisen, dass den Therapeuten ein Verschulden trifft und er überhaupt einen Ratschlag erteilt hat.

Wesentlich gravierender sind die Fälle, in denen ein Therapeut von der Einnahme eines ärztlich verordneten Medikaments abrät. Ist für den Therapeuten erkennbar, dass der Patient seinem Rat folgt und dass dadurch Schäden entstehen können, kommt eine Strafbarkeit wegen fahrlässiger Körperverletzung oder fahrlässiger Tötung in Betracht. Auch hier muss sich der Therapeut, sofern er eine Meinung abgibt, von der Verbindlichkeit seiner Aussage distanzieren. Er sollte den Patient darauf hinweisen, dass dieser sich bei Zweifeln an der ärztlichen Verordnung einen zweiten ärztlichen Rat einholen sollte. Anderenfalls kann es einem Therapeuten ähnlich ergehen wie einem Heilpraktiker, der seinen Patienten vom Befolgen ärztlicher Verordnungen abrät und abweichende eigene Verordnungen ausstellt. In diesen Fällen ist der Heilpraktiker, der als Heilkundiger ebenfalls ein gesteigertes Vertrauen der Patienten in Anspruch nimmt, strafrechtlich verantwortlich. Wenn er trotz erkennbarer Schädigungen bei seiner Empfehlung bleibt und weiß, dass Patienten diese befolgen werden, kommt eine Strafbarkeit mit Vorsatz und nicht nur wegen Fahrlässigkeit in Betracht. Denn in einem solchen Fall nimmt der Heilkundige billigend in Kauf, dass etwas passiert.

Philipp Groteloh

\section{$\Rightarrow$ Wirft auch Ihr Berufsalltag rechtliche Fragen auf? Dann schreiben Sie an Simone.Gritsch@thieme.de.}

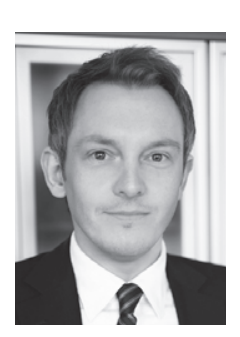
seit 2007 Rechtsanwalt und seit 2012 Fachanwalt für Verwaltungsrecht. 